\title{
“...the luthenist!”: ambivalências e desvios nas regravações de
}

\section{Julian Bream}

\author{
Sidney Molina
}

Faculdade Santa Marcelina, FMU/FIAM-FAAM (SP), IECG (PA) | Brasil

Resumo: A morte recente do violonista Julian Bream (1933-2020) tem motivado uma reavaliação de seu amplo legado artístico. O presente artigo aprofunda a análise da discografia do músico inglês em relação à de seu antecessor, Andrés Segovia, a partir da teoria da influência de Harold Bloom (1930-2019), que foi inicialmente proposta em nossa tese de doutorado (MOLINA, 2006). Tomando como base a divisão de seus 50 álbuns em fases inspiradas nas categorias bloomianas, procedemos a uma análise mais detida das regravações triplas, quádruplas ou quíntuplas de certas obras por Bream.

Palavras-chave: Julian Bream; Andrés Segovia; Harold Bloom; influência; discografia.

\begin{abstract}
The recent passing of English guitarist Julian Bream (1933-2000) has motivated a reevaluation of his artistic legacy by critics around the world. The current article reads the relationship between Bream's discography and that of his predecessor, Andrés Segovia, in light of Harold Bloom's theory of influence, methodology first proposed and defended in my 2006 doctoral dissertation. After dividing Bream's fifty albums in phases inspired by Bloomian categories, the article carefully attends to the works repeatedly recorded by Bream, in particular, those to which he returns three or more times.
\end{abstract}

Keywords: Julian Bream; Andrés Segovia; Harold Bloom; influence; discography. 
Dedicado à memória de Antônio Augusto - à lembrança de nossos encontros em Belém do Pará

\begin{abstract}
A influência poética, para muitos críticos, é simplesmente algo que acontece, uma transmissão de ideias e imagens, e o surgimento ou não de angústia no poeta posterior é visto como uma questão de temperamento e circunstância. Mas o efebo jamais poderá ser Adão no nascer da aurora. Os originais já existiram e já nomearam todas as coisas. E é o peso, agora, de retirar esses nomes que dá impulso às verdadeiras guerras combatidas sob o estandarte da influência poética, guerras declaradas pela perversidade do espírito contra a riqueza acumulada por ele, a riqueza da tradição. (BLOOM apud NESTROVSKI, 1996, p. 110)
\end{abstract}

Nome central dos estudos literários a partir da década de 1970, o crítico Harold Bloom (19302019) morreu em 14 de outubro de 2019. Dono de uma memória análoga à imagem borgiana da "Biblioteca de Babel”, ele passava, em seus cursos, longos momentos citando de memória cenas inteiras de Shakespeare ou poemas de Emily Dickinson. Embora ciente das diversas transmigraçóes de sua (hoje célebre) teoria da influência para outras formas artísticas - o que inclui a música - ele mesmo nunca se atreveu a emitir juízos sobre composição ou interpretação musical.

Com Mabler em Schoenberg: angústia da influência na Sinfonia de Câmara n.1 (2001), inicialmente publicado como dissertação de mestrado, ${ }^{1}$ dediquei-me com afinco à empresa de testar as elucubrações bloomianas no contexto da música instrumental, o que exigiu um esforço conceitual extra para adaptá-las às particularidades de uma linguagem não verbal.

Esses estudos prosseguiram na tese de doutorado O violão na Era do Disco: interpretação e desleitura na arte de Julian Bream (2006), ${ }^{2}$ que procurou ampliar esse escopo desde o campo da composição para o da teoria da performance e, mais especificamente, para o mundo do violão, tomando as relações de influência entre Andrés Segovia e Julian Bream.

Em um único breve encontro que tive com Bloom, ocorrido em sua casa, nas imediações da Yale University, em New Haven (CT), em outubro de 2012 - mais de 11 anos após a defesa do

\footnotetext{
${ }^{1}$ Lançado também como livro: MOLINA, Sidney. Mabler em Schoenberg: angústia da influência na Sinfonia de Câmara n.1. São Paulo: Rondó, 2003.

${ }^{2}$ Defendida no Programa de Comunicação e Semiótica da PUC-SP sob a orientação do Prof. Dr. Arthur Rosenblat Nestrovski.
} 
mestrado e 6 anos após o doutorado -, ele (para minha surpresa), revelou ter lido o livro Mabler em Schoenberg (original em português) e acompanhado com interesse os argumentos por entre as tecnicalidades das análises musicais. Entreguei em mãos, nesse dia, uma cópia encadernada da tese de doutorado. Ao ler o título ele exclamou: “Oh, Julian Bream...the luthenist!”.

Bream (1933-2020) morreu exatamente 10 meses após Bloom, em 14 de agosto de 2020. Músico e crítico foram da mesma geração, viveram no mesmo mundo.

A poesia, segundo Bloom, sempre começa quando alguém que será um poeta lê um poema. $\mathrm{E}$ para ver a compreensão plena que tem deste poema, teremos de ver o poema que ele mesmo escreverá, que será, assim, a sua própria leitura.

Se falarmos de dois intérpretes fortes - como Segovia e Bream -, por analogia, é a escuta musical que levará à prática interpretativa. Essa leitura-escuta será, no sentido de Bloom, necessariamente uma desleitura ou desapropriação poética. (BLOOM, 1991b, p. 117)

Nesse contexto, a encarnação poética, isto é, o que faz de um poeta, poeta - ou de um músico, músico - passa necessariamente pela luta artística que o artista mais jovem trava com o seu precursor direto, o seu pai poético.

Portanto - adaptando Bloom -, um “instrumentista efebo” deverá desler o seu precursor para que a sua performance não seja epígona, idealizada, fraca. Isso não significa que ele imitará a maneira de tocar de seu precursor, seu som, sua escolha de repertório, sua retórica: justamente o contrário, pois, para Bloom, “já que a influência poética é necessariamente desapropriação, uma tomada ou feitura errônea da herança, é de se esperar que tal processo de má-formação ou desinterpretação vá, no mínimo, produzir desvios de estilo entre poetas fortes” (BLOOM, 1995, p. 31).

Nem sempre plenamente compreendido - mesmo em outros estudos engajados na análise musical a partir da teoria de Bloom ${ }^{4}$ - esse ponto merece atenção especial: a influência forte, no

\footnotetext{
${ }^{3}$ Este primeiro trecho do presente artigo faz uso, de maneira livre, de ideias e citaçôes presentes nos capítulos "A dialética pragmática de Harold Bloom" (MOLINA, Mabler em Schoenberg: op.cit., p.1-21) e "Performance musical como desleitura" (MOLINA, O violão na Era do disco: op.cit. p. 1-35).

${ }^{4}$ Uma abordagem - a nosso ver distorcida - da teoria de Bloom aplicada aos estudos musicais aparece em STRAUS, 1990.
} 
sentido do crítico estadunidense, distingue-se das citaçôes, das aspas, da incorporação controlada e consciente das fontes passadas; é um ponto fulcral da arte dos artistas, a voz (ou o fantasma) de um outro dentro das obras (não das pessoas); influência, para Bloom, é desvio sobre o precursor, é enfrentar os custos de tentar dar à luz à si mesmo como artista.

Como inspiração para a constituição de uma forma mais pragmática (no sentido de menos idealizada) de crítica, Bloom elabora um mapa de “razões revisionárias”, um ciclo sêxtuplo que sugere as principais etapas da encarnação poética e da dialética da influência. Essas categorias podem também ajudar-nos a compreender os movimentos de desleitura atuando entre intérpretes de geraçóes diferentes, tal como na análise da discografia de Bream superposta à de Segovia.

Esses estágios jamais são aplicados literalmente, são apenas pistas da dialética pragmática da influência. Três momentos principais a resumem: o desvio inicial irônico sobre a obra do precursor; a imaginação criativa hiperbólica sobre a obra do precursor; e a projeção ou introjeção do precursor. O ciclo móvel de Bloom participa, a seu modo, tanto de momentos e movimentos internos de um texto poético (o que seria, para nós, a análise das interpretações musicais elas mesmas) quanto marca, também, o desenvolvimento vital do poeta-como-poeta diante do Pai Poético que o elegeu-enquantofoi-eleito (o que se aplicaria aos movimentos de expansão e retração de uma trajetória artística, desde o início até suas fases finais).

O foco na discografia faz uso, obviamente, do fato de que Bloom - aqui também na esteira de Borges - desloca a questão dos sentidos propriamente literários da literatura para a leitura, isto é, estabelece uma relação entre leitura e escrita que, no nosso caso, pode ser parodiada para a relação entre escuta musical e performance:

o ouvinte de uma gravação musical está para o intérprete assim como o intérprete está para o seu precursor. Por conseguinte, todo ouvinte é um efebo, toda gravação musical um precursor, e toda escuta musical um ato de influência, ou seja, o ato de ser influenciado pela gravação e de influenciar qualquer outro ouvinte para quem seja comunicada a sua escuta. (BLOOM, 1991b, p. 106-7)

Julian Bream lançou 50 discos durante sua carreira de intérprete: o primeiro aos 22 anos, o último aos 62 (sem contar relançamentos, coletâneas e registros de recitais ao vivo que vieram à luz após a aposentadoria). 
Foram sete LPs de alaúde solo, sendo três deles integralmente dedicados à música de John Dowland; e cinco discos com o tenor Peter Pears (1910-86).

Em nossa classificação - inspirada diretamente nas categorias de Bloom -, a primeira fase da discografia de Bream (o desvio irônico sobre o antecessor) compreende os seus primeiros seis LPs, gravados entre 1955 e 1958, quando contava menos de vinte e cinco anos de idade. ${ }^{5}$ São anteriores ao contrato com a RCA que acompanhará as quatro fases seguintes; portanto, nenhuma dessas gravaçóes está incluída na caixa Classical Guitar Anthology: Julian Bream - The Complete RCA Album Collection (RCA/SONY, 2013), composta por 40 CDs e 2 DVDs. Dos seis LPs que compóem essa primeira fase, em três Julian Bream apresenta-se ao alaúde, e não ao violão; e dois desses discos incluindo o primeiro de sua carreira - foram trabalhos camerísticos em duo de voz e alaúde com o tenor Peter Pears. Em seu segundo LP de violão solo, de 1956, ele faz aquela que parece ser a primeira gravação integral dos Cinco prelúdios de Villa-Lobos.

O segundo período (a complementação do precursor na obra do artista mais novo) vai de seus vinte e seis aos trinta e um anos de idade, e começa com a assinatura de contrato com a gravadora RCA, com a qual terá uma ligação de mais de trinta anos. São nove discos nesse período - entre 1959 e 1964: mais dois discos com o tenor Peter Pears (um ao vivo ao alaúde e outro ao violão), dois nos quais atua junto a agrupamentos orquestrais, um com o seu próprio ensemble de música antiga (o Julian Bream Consort), um de alaúde solo, e três de violão solo. Aqui Bream grava as primeiras obras dedicadas a ele por compositores ingleses, como a Sonatina de Lennox Berkeley (1903-1989), e o Concerto para violão e orquestra de Malcolm Arnold (1921-2006).

Faz parte do terceiro período discográfico uma histórica tetralogia de discos: Baroque Guitar (1965), 20th Century Guitar (1966), Classic Guitar (1968) e Romantic Guitar (1970), álbuns que são entremeados por discos de alaúde e também com o cravista George Malcolm. Nesses quatro álbuns Julian Bream parece inverter o conceito discográfico de Segovia - o "LP recital” - rumo a um conceito de discos temáticos, em um projeto que ostenta uma retórica que denominamos "instrução sonora”, o disco como "ensaio sem palavras". Entre as novas obras apresentadas está o emblemático Nocturnal

\footnotetext{
${ }^{5}$ Para esta rápida síntese da carreira discográfica de Bream lida a partir das categorias de Harold Bloom tomamos como parâmetro nosso artigo "Julian Bream: interpretação musical como obra autoral", escrito e publicado no dia exato da morte do violonista inglês, 14/8/2020, no Acervo Digital do Violão Brasileiro (ver:

https://www.violaobrasileiro.com.br/blog/julian-bream-interpretacao-musical-como-obra-autoral/368).
} 
de Benjamin Britten (1913-76), saudado como uma das grandes composiçóes para violão em toda a história do instrumento. No vocabulário de Bloom o momento pode apontar para uma retração de significado na interpretação sonora, o que esvazia simultaneamente o papel do antecessor.

No período seguinte - o do deslocamento na direção de um contra-sublime, isto é, de um sublime contrário ao do precursor - serão mais onze discos, gravados entre 1971 e 1978, quando o artista contava entre 38 e 45 anos. Apenas quatro são de violão solo, e - ainda assim -, em dois deles, há a participação de agrupamentos orquestrais. Dois desses quatro discos de violão solo são dedicados integralmente a Villa-Lobos, o de 1971, que inclui a famosa gravação do Concerto com a Sinfônica de Londres regida por André Previn, e o que contém a integral dos estudos, em 1977. Em outros dois discos Bream atua como solista da Monteverdi Orchestra sob a direção de Eliot Gardiner. Também são dois discos de alaúde solo, com um deles - mais uma vez - dedicado integralmente a Dowland. Finalmente, há os três discos em duo com John Williams, o último dos quais gravado ao vivo. Em sete dos onze trabalhos há outros músicos, ensembles ou orquestras ao lado de Bream. Também está nessa fase o álbum Julian Bream 70s, disco com composições escritas para ele por Richard Rodney Bennett (1936-2012), Alan Rawsthorne (1905-1971), Lennox Berkeley (1903-1989) e William Walton (19021983 ) - a primeira gravação das imediatamente célebres "Five Bagatelles”. Há também a importante recuperação para o repertório das “Rossinianas” de Mauro Giuliani (1781-1829) no álbum de 1974.

No quinto período, de plena maturidade, que vai de 1979 a 1991, são doze anos de trabalho: ele entra nessa fase com 46 anos e sai com 58. É quando encara de frente - a seu modo - o repertório espanhol imortalizado por Segovia. Dos onze discos lançados no período, sete são exclusivamente de música espanhola, e um traz obras orquestrais de Brouwer e Rodrigo. Os outros são Dedication, onde predominam obras de compositores ingleses, Two Loves, com música de Dowland intercalada com a recitação de poemas de Shakespeare, e o segundo disco do Julian Bream Consort. Obras seminais de Peter Maxwell Davies (1934-2016) e Hans Werner Henze (1926-2012) são adicionadas ao repertório. É onde se dá a ascese que permite ao poeta, afinal, interpretar seu precursor e a apropriação do "poeta mais velho", aquilo que Bloom nomearia como o retorno do precursor como se fosse, ele mesmo, obra do artista mais novo.

$\mathrm{Na}$ coda de sua discografia, Bream lança mais quatro discos: um com orquestra (com sua quarta gravação do Concerto de Aranjuez), um de música do século 20, um inteiramente dedicado a Bach e 
mais um contendo três grandes sonatas para violão. São introduzidas em sua discografia obras originais de Toru Takemitsu (1930-96) e Leo Brouwer (1939), o resgate de Antonio José (1902-1936) e um - até então recusado - autor segoviano: Mario Castelnuovo-Tedesco (1895-1968). Esses últimos álbuns também não estão inseridos na caixa da RCA. ${ }^{6}$

O projeto discográfico de Bream envolve igualmente um número grande de regravaçóes, o que mostra não só a importância do contexto (do conceito do disco, do instrumento utilizado etc.), mas também uma verdadeira perseguição às nuances e sentidos de obras específicas: é este ponto que vamos explorar na seção final deste artigo.

Seja em música clássica ou música popular, uma carreira discográfica longa pressupóe, por várias razões - das exclusivamente artísticas às norteadas por oportunidades comerciais - regravaçóes de certos temas ou obras. Um exemplo de justificativa natural para uma regravação está na relação de Julian Bream com os Estudos de Villa-Lobos: ele já havia gravado, em diferentes LPs lançados em 1962, 1966 e 1971, versóes dos Estudos n.5, n.7, n.8 e n.11; nada mais natural que, ao encarar sua integral dos 12 Estudos (em 1977), tenha regravado esses estudos para apresentar o set completo em versão homogênea.

A partir de um certo ponto, entretanto, a regravação passa a não ter justificativas ou explicações vindas de aspectos exteriores às próprias relações sonoras. Do ponto de vista da teoria de Harold Bloom, essa ênfase “mais-que-normal” em certos pontos do repertório emerge como sintoma da angústia, como momento do complexo desvio sobre o antecessor.

Se, no caso de Bream, desprezarmos as dezenas de gravaçôes duplicadas de peças, às vezes realizadas em fases muito distantes da carreira, ou então oportunamente inseridas em projetos de álbuns com repertórios específicos, podemos nos concentrar apenas em um número menor de obras gravadas por ele três vezes ou mais (há peças registradas por ele três, quatro e até mesmo cinco vezes,

\footnotetext{
${ }^{6}$ Em meu canal no YouTube há um vídeo (publicado 3 dias após sua morte) em que apresento resumidamente (em 27 minutos) a discografia completa de Julian Bream. O link é: https://youtu.be/LsIq31ZPJ20
} 
sempre em gravações comerciais lançadas em LPs ou CDs). ${ }^{7}$

No caso de um músico com a responsabilidade artística de Julian Bream, tais releituras constantes marcam tais peças com destaque especial, seja por trazerem ao artista um espaço privilegiado na busca de expressão e sentidos, seja por serem provocadas por algum tipo de insatisfação - como, por exemplo, travar uma luta interna incessante em busca de registros mais e mais satisfatórios. Tanto num caso como noutro parece haver na relação de Bream com essas peças um aspecto mobilizador de suas energias criativas que nos interessa de perto.

Que peças são essas?

Comecemos pelo alaúde, onde abundam mais as versôes triplicadas, quadruplicadas e até mesmo uma quíntupla.

Foram gravadas três vezes as seguintes peças de John Dowland: "The Frog Galliard”; "Can She Excuse"; "My Lady Hunsdon’s Puffe", "Semper Dowland, Semper Dolens" e "Melancholy Galliard”. ${ }^{10}$

Duas peças de Dowland receberam um total de quatro gravações: “Queen Elizabeth's Galliard, ${ }^{11}$ e "Tarleton's Resurrection”"12 que - numa das mais inesperadas ousadias já realizadas no mundo das regravaçốes em música clássica - recebe duas versões no mesmo álbum, Two Loves (1988), ambas separadas apenas pela narrativa da cena 3 do ato IV de Othello, de Shakespeare, pela atriz Peggy Ashcroft. A segunda interpretação dura cerca de 10 segundos a mais do que a primeira.

Enfim, a campeã das regravaçôes: "Lachrimae Pavan”, também de Dowland, que recebeu 5 registros diferentes de Bream entre 1957 e $1988 .{ }^{13}$

\footnotetext{
${ }^{7}$ Aqui falamos, obviamente, sempre de takes diferentes: são regravaçốes de fato, e não relançamentos das mesmas faixas em outros formatos ou coletâneas.

${ }^{8}$ Registrada em versão alaúde solo no LP The Dances of Dowland, de 1967; em versão de ensemble - atribuída a Thomas Morley - no LP An Evening of Elizabethan Music, de 1962; e de novo em versão solo em Two Loves, de 1988.

${ }^{9}$ Registrada em versão de ensemble no LP An Evening of Elizabethan Music, de 1962; em versão de alaúde e voz no LP Elizabethan Lute Songs, de 1970; e em alaúde solo em Two Loves, de 1988; para além, há uma versão de alaúde com outro título, "The Earl of Essex Galliard”, gravada em Dances of Dowland, de 1967.

${ }^{10}$ Registradas conjuntamente nos LPs Julian Bream Plays Dowland, de 1957; The Dances of Dowland, de 1967; e Two Loves de 1988.

${ }^{11}$ Registrada nos LPs Julian Bream Plays Dowland, de 1957; Julian Bream in Concert, de 1963; Lute Music of Royal Courts of Europe, de 1966; e Two Loves de 1988.

${ }^{12}$ Registrada em versão para ensemble no LP An Evening of Elizabethan Music, de 1962; em versão para alaúde solo no LP Julian Bream in Concert, de 1963; e, enfim, tocada duas vezes ao alaúde em Two Loves, de 1988.

${ }^{13}$ Ela aparece em versão de alaúde solo nos LPs Julian Bream Plays Dowland, de 1957; The Dances of Dowland, de 1967; e Two Loves, de 1988; e em versão de ensemble nos LPs An Evening of Elizabethan Music, de 1962; e Fantasies, Ayres e Dances, de 1987.
} 
Já entre as peças para violão gravadas ao menos três vezes por Bream há o Prelúdio n.4 de VillaLobos (Bream fez duas integrais dos Cinco Prelúdios, em 1956 e 1971, mas havia registrado o Prelúdio n.4 separadamente em 1962). ${ }^{14}$

Outras obras que receberam triplo registro fonográfico são o "Largo" da Fantasia op.7 de Fernando Sor, ${ }^{15}$ o "Fandanguillo" de Joaquín Turina, a "Homenaje pour le tombeau de Claude Debussy" de Manuel de Falla, ${ }^{16}$ e as "Sarabande” e "Bourrée” da Suite BWV 996 de Bach. ${ }^{17}$

Finalmente, Julian Bream gravou quatro vezes, de forma integral, o "Concierto de Aranjuez", de Joaquín Rodrigo. ${ }^{18}$

Se tomamos essas obras na comparação com a discografia de Segovia, é possível extrair algumas conclusões interessantes. ${ }^{19}$

Segovia gravou pouco Dowland (há registros de algumas obras favoritas de Bream, como "Melancholy Galliard” e "My Lady Hunsdon’s Puffe”), mas nunca com destaque chamativo em sua discografia. O mesmo ocorre com a "Sarabande" e a "Bourrée" da Suite BWV 996, gravadas por Segovia em 1947 em 78 rpm (a "Bourrée” surgiria também num LP de 1954), com a função nítida de completar os programas dos álbuns.

Da mesma forma, apesar de se dedicar a Sor desde suas primeiras gravaçôes em $78 \mathrm{rpm}$, tendo registrado dezenas de obras do compositor catalão (várias delas mais de uma vez), Segovia só viria a gravar o "Andante Largo" da Fantasia op.7 aos 86 anos, no LP Recital Íntimo, de 1973. O maestro espanhol tampouco gravou o Prelúdio n.4 de Villa-Lobos (dos Cinco Prelúdios ele registraria apenas os de n.1 e n.3).

\footnotetext{
${ }^{14}$ O Prelídio n.4 foi gravado no LP Villa-Lobos and Torroba, de 1956; no LP Popular Classics for Spanish Guitar, de 1962; e no LP Julian Bream Plays Villa-Lobos, de 1971.

${ }^{15}$ Nos LPs Sor, Turina and Falla, de 1956; Baroque Guitar, de 1965; e Music of Spain vol. IV: The Classical Heritage, de 1980.

${ }^{16}$ Elas estão juntas nos álbuns Sor, Turina and Falla, de 1956; Popular Classics for Spanish Guitar, de 1962; e Music of Spain vol VII - A Celebration of Andrés Segovia, de 1984.

${ }^{17}$ Gravadas - além das versões integrais da suíte, presentes em J. S. Bach Suites n.1 and n.2, de 1964; e J. S. Bach, de 1994 -, também no LP A Bach Recital for the Guitar, de 1957.

${ }^{18}$ As versốes estão em: Julian Bream. Rodrigo, Britten, Vivaldi, de 1964 (regência de Colin Davis); Julian Bream. Rodrigo and Berkeley Concertos, de 1975; Music of Spain vol VIII - Rodrigo, de 1984 (ambas com regência de Eliot Gardiner); e Julian Bream: Rodrigo, Tekemitsu, Arnold, de 1993 (regência de Simon Rattle).

${ }^{19}$ A discografia de Segovia acha-se até hoje dispersa em coletâneas de qualidade irregular. Para uma visão de conjunto de seu acervo em discos de $78 \mathrm{rpm}$ e LPs, ver os dois vídeos que postei em meu canal do YouTube sobre o tema: Segovia: discografia parte 1 (78 rpm), https://youtu.be/aGXW_28CJIM; e Segovia:discografia parte 2(LPs),

https://youtu.be/HWwRhyy9HIO
} 
Sob a ótica da comparação, portanto, as peças mais importantes são "Homenaje pour le tombeau de Claude Debussy”, de Manuel de Falla, e, ainda mais - por ser obra dedicada a Segovia e uma de suas favoritas - o "Fandanguillo" de Joaquín Turina.

Falla escreveu sua única obra original para violão em 1920 a partir de insistência de Miguel Llobet (1878-1938). Segovia a havia gravado em 1953 (no LP An Andres Segovia Concert). A primeira versão de Bream, presente em seu primeiro LP de violão solo, de 1956, é serena e fúnebre, quase “alaudística”, se assim é possível dizer, e nada tem do espanholismo nervoso presente na interpretação de Segovia feita poucos anos antes.

Segovia registrou o "Fandanguillo" de Turina magistralmente em 1928 e 1949, em discos de 78 $\mathrm{rpm}$. A versão inaugural de Bream surge como um irônico sintoma primário de defesa, uma respeitosa aceitação do repertório dedicado a Segovia.

Em suas segundas interpretações, "Fandanguillo" e "Homenaje" também aparecem juntas no LP Popular Classics for Spanish Guitar, de 1962. Se as primeiras gravaçôes soavam uma pouco secas e metálicas, se o violão Quine não era um instrumento de grandes recursos, e se tudo parecia um pouco cuidadoso e estudado demais, a fluência conquistada e os magníficos instrumentos de Robert Bouchet acham-se, por outro lado, submetidos a um excesso de reverberação; tudo é um pouco exagerado, hiperbólico, e essa deve ter sido uma das razóes para que Bream decidisse ainda gravá-las mais uma vez no futuro.

É com liberdade, coragem e espírito de enfrentamento que Bream decide, então, abrir seu LP de 1984 - não à toa intitulado Music of Spain vol VII: A Celebration of Andrés Segovia - com sua terceira e definitiva gravação do "Fandanguillo" op. 36 de Turina. É sua gravação mais equilibrada: Bream parece enfrentar a peça com sabedoria e simplicidade - ele não quer mais competir com Segovia, sobretudo com o histórico registro de 1929, mas parece ser ele o artista mais velho, o fundamento, a referência, e Segovia um jovem intempestivo que busca afirmar-se. Dá-se a reversão da anterioridade. 
No mesmo disco está também a terceira performance da "Homenaje” de Falla: a cada versão ele foi se distanciando mais e mais de Segovia. A obsessão de Bream com a obra parece ter sido recompensada: ambiência, sonoridade e tempo estão perfeitos, a marcha fúnebre funde-se com o ritmo de habanera, e o tema de "La soirée dans Grenade" (de Debussy) emerge sem ruptura.

Para Bloom toda interpretação forte - e isso parece valer também para performances musicais é necessariamente inautêntica; é, mesmo, uma desinterpretação: "Recapitulando: todo poema é o desvirtuamento de um poema-pai. Um poema não é a superação de uma angústia, mas a própria angústia. Interpretação não existe: só existe desinterpretação” (BLOOM, 1991a, p. 133). Bream jamais gravou Ponce, o compositor mais amado por Segovia; e Segovia, por seu turno, nunca registrou "Lachrimae” ou o "Aranjuez". Na escuta de obras como "Fandanguillo" e "Homenaje”, a escritura musical é o pretexto de um jogo artesanal-auditivo que - realizado na materialidade concreta de cordas e madeira - se dá em meio a desvios, hipérboles e ambivalências.

\section{REFERÊNCIAS}

BLOOM, Harold. A angústia da influência: uma teoria da poesia. Tradução de Arthur Nestrovski. Rio de Janeiro: Imago, 1991a. . Cabala e crítica. Tradução de Monique Balbuena. Rio de Janeiro: Imago, 1991 b.

Imago, 1995. . Um mapa da desleitura. Tradução de Thelma Médici Nóbrega. Rio de Janeiro:

BREAM, Julian. Classical Guitar Anthology: Julian Bream - The Complete RCA Album Collection (box com 40 CDs e 2 DVDs). RCA/SONY, 2013.

NESTROVSKI, Arthur. Ironias da modernidade. São Paulo: Ática, 1996.

MOLINA, Sidney. Julian Bream (1933-2020): discografia [vídeo]. In: Sidney Molina (canal no YouTube), 17/08/2020. Disponível em: https://www.youtube.com/watch?v=LsIq31ZPJ20\&t=10s (acesso realizado em 28/11/2020). . Julian Bream: interpretação musical como obra autoral (artigo). In: Acervo Digital do Violão Brasileiro (portal online), 14/08/2020. Disponível em https://www.violaobrasileiro.com.br/blog/julian-bream-interpretacao-musical-como-obra- 
autoral/368 (acesso realizado em 28/11/2020). . Mabler em Schoenberg: angústia da influência na Sinfonia de Câmara n.1. São Paulo: Rondó, 2003.

. O violão na Era do disco: interpretação e desleitura na arte de Julian Bream. Tese de doutorado defendida no Programa de Comunicação e Semiótica da PUC-SP (2006). . Segovia: discografia parte $1(78 \mathrm{rpm})$ [vídeo]. In: Sidney Molina (canal no YouTube), 13/09/2020. Disponível em: https://www.youtube.com/watch?v=aGXW_28CJlM\&t=1s (acesso realizado em 28/11/2020).

. Segovia: discografia parte 2 (LPs) [vídeo]. In: Sidney Molina (canal no YouTube), 26/09/2020. Disponível em: https://www.youtube.com/watch? $v=H W w R h y 9 H I 0 \& t=12 s$ (acesso realizado em 28/11/2020).

STRAUS, Joseph N. Remaking the Past. Musical Modernism and the Influence of the Tonal Tradition. Cambridge: Harvard University Press, 1990.

\section{SOBRE O AUTOR}

Sidney Molina é Coordenador do Curso de Pós-graduação em Violão: pedagogia e performance da Faculdade Santa Marcelina (SP) e professor na graduação dos cursos de música do FMU/FIAM-FAAM (SP) e Instituto Estadual Carlos Gomes (PA). Fundador do Quaternaglia Guitar Quartet, é autor de dois livros e, ao longo de 28 anos, tem atuado em eventos artísticos e acadêmicos no Brasil, Estados Unidos, América Latina, Europa, Japão e Austrália. ORCID: https://orcid.org/0000-0002-0433-6666. E-mail: sidney@quaternaglia.com.br 